\title{
Growth rate variation of the stalked barnacle Pollicipes pollicipes (Crustacea: Cirripedia) using calcein as a chemical marker
}

\author{
David Jacinto ${ }^{1,2}$, Nélia Penteado ${ }^{1,2}$, Diana Pereira ${ }^{1,2}$, Alina Sousa ${ }^{1,2}$, Teresa Cruz ${ }^{1,2,3}$ \\ ${ }^{1}$ MARE - Marine and Environmental Sciences Center, Laboratório de Ciências do Mar, Universidade de Évora, \\ Apartado 190, 7520-903 Sines, Portugal. E-mail: djacinto@ uevora.pt \\ ${ }^{2}$ Centro de Oceanografia, Universidade de Évora, Portugal. \\ ${ }^{3}$ Departamento de Biologia, Escola de Ciências e Tecnologia, Universidade de Évora, Portugal.
}

\begin{abstract}
Summary: This study describes the use of calcein as a chemical tagging methodology to estimate growth rate variation of the stalked barnacle Pollicipes pollicipes, an ecologically important intertidal species and economic resource, in SW Portugal. Calcein tagging had a high success rate (94\%) in marking both juvenile and adult barnacles for a period of 2.5 months, providing a valuable method for obtaining reliable data in growth studies of $P$. pollicipes. Growth rate decreased with barnacle size and was highly variable amongst individuals, particularly in smaller barnacles. No effect of shore level on barnacle growth was detected. Growth rates were higher in smaller juvenile barnacles, peaking at a 1.1-mm monthly increment in rostro-carinal length (RC) for individuals with $\mathrm{RC}=5 \mathrm{~mm}$, and decreased with barnacle size (monthly growth rates of $0.5 \mathrm{~mm}$ for adult barnacles with RC $\sim 12.5 \mathrm{~mm}$ ). Growth rates observed in adults with commercial interest (RC $\geq 18 \mathrm{~mm})$ was $<0.25$ $\mathrm{mm}$ per month. The advantages of tagging $P$. pollicipes with calcein were the possibility of mass marking individual barnacles of different size cohorts within a short period (less than 1 day of manipulation); and reduced time of fieldwork, which is very important because this species inhabits very exposed rocky shores.
\end{abstract}

Keywords: stalked barnacle; Pollicipes; growth rate; calcein; tagging; intertidal; Portugal.

Variación de la tasa de crecimiento del percebe Pollicipes pollicipes (Crustacea: Cirripedia) utilizando calceína como marcador químico

Resumen: Este estudio describe el uso de calceína como marcador químico para estimar la variación de la tasa de crecimiento del percebe Pollicipes pollicipes, una especie ecológicamente importante del intermareal rocoso y un importante recurso económico en la Península Ibérica. El uso de calceína tuvo una alta tasa de éxito (94\%) para el marcaje de juveniles y adultos durante un período de 2.5 meses, proporcionando un método valioso para obtener datos fiables. La tasa de crecimiento disminuyó con el tamaño y fue muy variable entre individuos, principalmente en los percebes más pequeños. No se detectó ningún efecto del nivel intermareal en el crecimiento de percebes. Las tasas de crecimiento fueron más altas en los percebes juveniles más pequeños, alcanzando un máximo de $1.1 \mathrm{~mm}$ de incremento mensual de longitud rostro-carenal (RC) para individuos con $\mathrm{RC}=5 \mathrm{~mm}$, y disminuyeron con el tamaño del percebe (tasas de crecimiento mensual de $0.5 \mathrm{~mm}$ para percebes adultos con RC $12.5 \mathrm{~mm}$ ). Las tasas de crecimiento observadas en los adultos con interés comercial ( $\mathrm{RC} \geq 18 \mathrm{~mm}$ ) fueron $<0.25 \mathrm{~mm}$ por mes. Las ventajas de la marcación de $P$. pollicipes con calceína fueron: la capacidad de tinción en masa de percebes de diferentes cohortes en un período corto (menos de 1 día de manipulación) y, por tanto, la reducción del tiempo de trabajo de campo, que es muy importante ya que esta especie habita costas rocosas muy expuestas.

Palabras clave: percebes; Pollicipes; tasa de crecimiento; calceína; marcación; intermareal; Portugal.

Citation/Como citar este artículo: Jacinto D., Penteado N., Pereira D., Sousa A., Cruz T. 2015. Growth rate variation of the stalked barnacle Pollicipes pollicipes (Crustacea: Cirripedia) using calcein as a chemical marker. Sci. Mar. 79(1): 117-123. doi: http://dx.doi.org/10.3989/scimar.04135.08B

Editor: P. Abelló.

Received: August 7, 2014. Accepted: January 7, 2015. Published: February 11, 2015.

Copyright: () 2015 CSIC. This is an open-access article distributed under the Creative Commons Attribution-Non Commercial Lisence (by-nc) Spain 3.0. 


\section{INTRODUCTION}

Pollicipes pollicipes is a common barnacle species on very exposed intertidal rocky shores from Brittany to Senegal, where it forms dense aggregates of individuals (Barnes 1996). It is a very important economic resource in Spain and Portugal, and is heavily exploited (Molares and Freire 2003, Jacinto et al. 2010). Despite its economic and ecological importance, several aspects of its biology and ecology are still poorly understood, most likely as a result of the difficulty associated with conducting ecological studies in the extreme exposed habitats where this species occurs (Barnes 1996, Cruz 2000, Cruz et al. 2010), and the difficulty of studying growth in pedunculate barnacles.

Growth studies of Pollicipes spp. are mostly based on population size structure analyses and estimates of growth rates of a few aged or un-aged individuals that are marked in the field (e.g. Page 1986, Phillips 2005, Cruz et al. 2010). Marking techniques of individuals in these studies include mapping individuals in relation to marks made in adjacent substrata, or using marks such as insect tags glued to the capitulum plates of suitably-sized individuals. However, these techniques are difficult to apply and maintain on very exposed shores where time to work is limited. Consequently, their success might be low and small animals may be very difficult to mark.

In stalked barnacles, peduncular growth mostly occurs in a narrow zone between the capitulum and the peduncle (Chaffee and Lewis 1988), and on the capitulum, primary plates (scuta, terga and carina) grow in thickness and area by laminar and marginal accretion over the whole inner surface from an underlying epidermis where the plates are embedded (Anderson 1994, Barnes 1996). The most widely used variable for growth and size structure studies in Pollicipes spp. is the maximum rostro-carinal length (RC) (Phillips 2005, Cruz et al. 2010, Boukaici et al. 2012), although other variables such as total length (Hoffman 1984), capitulum height (Page 1986, Cardoso and Yule 1995) and capitulum base diameter (Parada et al. 2012) have also been used.

Growth rates in Pollicipes spp. are highly variable in space and time (reviewed by Barnes 1996). Factors affecting barnacle growth may include immersion time and food availability, light, season, water temperature, microhabitat and population density. Previous observations of $P$. pollicipes growth patterns on the SW coast of Portugal (Cruz 1993, 2000, Cruz et al. 2010) suggest that growth rates vary with barnacle size, season and intertidal level. Cruz (2000) observed that on average un-aged juveniles $(\mathrm{RC}<10 \mathrm{~mm})$ grew by $0.47 \mathrm{~mm} \mathrm{RC}$ per month (winter, spring and summer), while un-aged adults $(\mathrm{RC}>10 \mathrm{~mm})$ grew by $0.11 \mathrm{~mm} \mathrm{RC}$ per month in summer and $0.47 \mathrm{~mm}$ RC per month in winter and spring. When monitoring the size of 11 individual barnacles that have recruited onto a cleared surface, Cruz et al. (2010) estimated an average growth of $1.3 \mathrm{~mm}$ $\mathrm{RC}$ per month during their first year. Size structure analyses of $P$. pollicipes attached directly to primary substratum and/or to the base of conspecifics evidenced that barnacles at the low tide level reached a higher maximum size, possibly indicating that growth at this tidal level was higher than at the high shore (Cruz et al. 2010).

The use of chemical tagging as a mass marking technique may provide new insights in growth rate variation in $P$. pollicipes, as a large number of individuals from different cohorts and habitats may be individually and simultaneously tagged and studied with relative ease and safety. Calcein $\left(\mathrm{C}_{30} \mathrm{H}_{26} \mathrm{~N}_{2} \mathrm{O}_{13}\right)$ is a fluorochrome that binds to calcium and becomes incorporated in calcified structures of growing animals when exposed to this chemical agent, and has been successfully used in ecological studies of several marine species (Moran 2000). Immersion in a calcein solution leaves a fluorescent mark in calcified structures, which is visible under epifluorescent microscopy and has been used to identify marked individuals and to estimate growth rates in several organisms, including fishes (Wilson et al. 1987, Leips et al. 2001, Frenkel et al. 2002), ascidians (Lambert and Lambert 1996), molluscs (Kaehler and McQuaid 1999, Moran 2000, Van der Geest et al. 2011), echinoderms (Russell and Urbaniak 2004, Ebert et al. 2008) and crustaceans (Helms 2004, Kilada et al. 2012).

Chemical tagging in stalked barnacles was first described by Helms (2004), who has successfully used calcein marks to study recruitment and juvenile growth patterns in Pollicipes polymerus. The fluorescent mark visible on the carbonate plates of the capitulum was used to distinguish old recruits (marked individuals) from the new ones (not marked) and also to estimate growth rates during the study period by measuring the marginal increment of the capitular plates after the calcein treatment.

In this study, we have adapted the calcein tagging methodology proposed by Helms (2004) in order to mark multiple juvenile and adult barnacles overnight, an important requirement in such extreme environments with small temporal windows of appropriate oceanographic conditions for fieldwork, and to estimate growth rate variation with intertidal vertical level and size of the stalked barnacle Pollicipes pollicipes in SW Portugal. We expected growth rates to decrease with barnacle size and vary with intertidal level (larger growth rates in low shore barnacles).

\section{MATERIALS AND METHODS}

\section{Study area}

This study was carried out between July and September 2012 at Cabo Sardão (SW Portugal; 37³6'25'N, $8^{\circ} 49^{\prime} 02^{\prime \prime} \mathrm{W}$ ), a very exposed headland of metamorphic schists, where $P$. pollicipes is abundant and also heavily exploited. As in other areas along the Portuguese coast, $P$. pollicipes abundance varies along the shallow subtidal/intertidal gradient (Sousa et al. 2013). Higher densities, percentage cover and biomass are observed on the mid-shore than on the low shore, yet low shore barnacles have a higher proportion of adults with moderate and high commercial value, while juveniles are 
relatively more abundant on the mid-shore (Sousa et al. 2013). For the purposes of the present study, two vertical levels were considered: 1 ) high, corresponding to the middle/upper intertidal level of $P$. pollicipes local distribution and 2) low, corresponding to the lower intertidal level of its local distribution.

\section{Animal collection and chemical marking}

On the 20th June 2012, during the morning low tide, several chips of rock with attached barnacle clumps (containing barnacles of different sizes) were detached from the intertidal substrate (in both the low and high vertical levels; $n=10$ and $n=16$, respectively) using a hammer and chisel, and transported to the laboratory in buckets. Barnacle clumps were immersed in containers of 10-15 L of filtered seawater at $200 \mathrm{mg}$ calcein $\mathrm{l}^{-1}$ and were continuously aerated with diffusive air stones for 20-22 hours. Barnacles were not fed during the marking period. Calcein solutions were made from a stock of $6.25 \mathrm{~g} \mathrm{l}^{-1}$ of calcein in distilled water and buffered to $c a . \mathrm{pH} 6$ with the addition of sodium bicarbonate to increase solubility (Wilson et al. 1987, Helms 2004). The next day, during the morning low tide, the barnacle clumps were transported back to the same shore area and fixed randomly to the rock with Z-Spar Splash Zone Epoxy (Kop-Coat Inc., Pittsburgh, PA), at the vertical level where they had been collected. On the $9^{\text {th }}$ September 2012, after a growth period in the field of 76 days, experimental clumps present at the study site were collected from the shore ( 3 from each intertidal level; the remaining barnacle clumps were kept in the intertidal area for further studies, or were either lost or had no barnacles attached at the time of collection), brought to the laboratory and frozen until further analysis. Chemical marking success was measured by dividing the number of individuals with fluorescent marks and the total number of animals retrieved from the field.

\section{Laboratorial analyses}

All barnacles $(\mathrm{RC}>1 \mathrm{~mm})$ present in each clump were unfrozen, detached, counted, measured with callipers $(\mathrm{RC}$, precision $=0.1 \mathrm{~mm})$ and immersed in commercial bleach (Sodium Hypochlorite 3.5\%) for 1 to 60 minutes, depending on barnacle size, in order to dissolve the soft tissues and separate the capitular plates from the rest of the body. The timing of the bleach bath was the minimum required to remove soft tissues, separate capitular plates and expose the edges and calcein marks under magnification. Initially, all smaller individuals (approx. $\mathrm{RC}<5$ ) were immersed for 1 minute. After a first visual inspection, if necessary, additional immersion time (in 1-min blocks) was added. Larger individuals (approx. RC 5-15 mm) were initially immersed in bleach for $5 \mathrm{~min}$, and if necessary, additional immersion time (in 5-min blocks) was added. Very large individuals (approx. RC>15) were initially immersed in bleach for $10 \mathrm{~min}$ and, if necessary, additional immersion time (in 10-min blocks) was added. Adult individuals required more time to prepare the plates for observation: more time immersed in bleach (up to 20 hours in a few cases); and if needed some abrasion with sandpaper or scrapper to remove calcareous algae and other organisms attached to the plates. The scutum and tergum of the capitular plates (both pairs; Fig. 1) were observed and photographed at an appropriate magnification (7-20x) under an epifluorescent dissecting microscope (Leica M165FC with a UV light source and GFP3 filter) equipped with a digital camera (Leica DF 295) connected to a computer. The entire initial capitular plates and/or its edges, if stained, fluoresced under appropriate light, while the new material did not. By measuring the amount of new material added to the capitular plates it was possible to estimate individual growth in Pollicipes polymerus (Helms 2004). Whenever calcein marks were identified, the following variables were measured with a digital image analysis software (Leica Application Suite v3.8) in each plate: the maximum length of each plate (scutum or tergum: $s c \_f$ or $\operatorname{tg} f$, respectively; Fig. 1) and the maximum length of the original plate at the time of marking (whose edges are detectable by the fluorescent calcein mark; scutum or tergum: sc_i or tg_i, respectively, Fig. 1).

\section{Data analyses}

Exploratory analyses included multiple pair-wise scatterplots and Pearson product-moment correlation tests to detect relationships and collinearity between measured variables. All maximum capitular plate lengths (sc_f and tg_f from both sides) were highly and positively correlated among each other and with RC ( $r>0.98, p<0.01$ for all paired comparisons, $215 \leq n \leq 259$ pairs of observations), suggesting that either plate could be used to study barnacle growth. All estimates of growth used in the present study were based on measurements made on the right scutum of each marked barnacle, which was the subset of data containing the fewest missing values (4.6\%). A total of 269 barnacle growth measurements (corresponding to 127 and 142 individuals from the low and high intertidal, respectively) were used.

In order to estimate growth in a unit that may be easily used for comparisons with other barnacle growth studies, a linear model describing the relationship between RC and the maximum right scutum length (sc) was applied ( $n=259$ paired data). Model coefficients ( $\mathrm{RC}=1.66^{*} \mathrm{sc}$; see results) were then used to convert all measurements made in the right scutal plates (sc_f and sc_i) into $\mathrm{RC}$ units (RC_f and RC_i, respectively). Growth rate $(\mathrm{dRC})$ was based on estimated $\mathrm{RC}$ values $\left(\mathrm{dRC}=\mathrm{RC} \_\mathrm{f}-\mathrm{RC} \_\mathrm{i}\right)$.

Monthly growth rate ( $\mathrm{dRC} 30)$ was estimated by dividing the growth rate (dRC) by the growing period in the field (2.53 months), assuming linear growth during that period.

In order to describe growth rate variation of $P$. pollicipes with size and tidal level, the response variable (monthly growth rate, dRC30) was modelled as a function of the explanatory variables, estimated barnacle initial size ( $\mathrm{RC} \_\mathrm{i}$, ranging from $0.14 \mathrm{~mm}$ to 20.95 $\mathrm{mm}$ ) and vertical level (low and high intertidal), using 

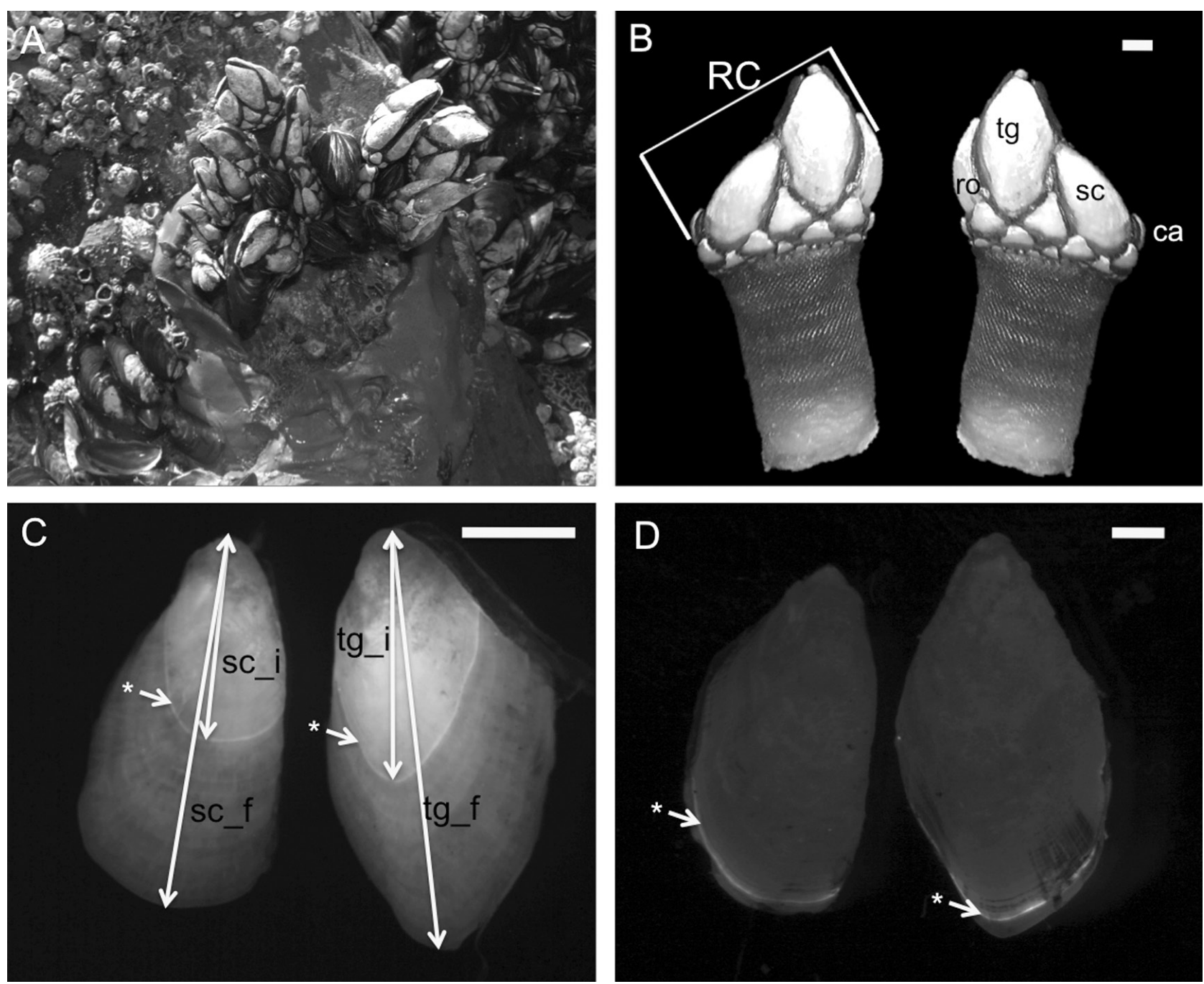

Fig. 1. - A, a clump of calcein marked barnacles fixed to the rocky substrate with marine epoxy; B, P. pollicipes lateral view, identifying capitular plate position (sc, scutum; tg, tergum; ro, rostrum; ca, carina) and measured variable (RC, maximum rostro-carinal length); $\mathrm{C}$, left side scutum and tergum plates from a marked juvenile barnacle (* indicates the edge of the calcein mark in the initial capitular plates), arrows show measured variables (sc i, initial scutum length: sc f, final scutum length; tg i i, initial tergum length; tg f, final tergum length) for each capitular plate; D, left side scutum and tergum plates from a marked adult $P$. pollicipes showing the calcein marks visible only at the edge of the initial capitular plate area $(*) .1-\mathrm{mm}$ scale bars are shown in images B, C and D

generalized additive models (Zuur et al. 2007). This model was used because exploration of data procedures revealed potential violation of homogeneity and non-linearity (Zuur et al. 2007). Comparisons of deviances of nested models (using an F-test) and graphical analysis of residuals distribution were carried out to identify and validate the optimal model (Zuur et al. 2007). Data exploration and analysis were performed using R software (www.r-project.org).

\section{RESULTS}

\section{Fluorescent marking success rate}

Fluorescent marks were observed in 282 barnacles (size range: $1.5 \mathrm{~mm}$ to $19.9 \mathrm{~mm}$ of $\mathrm{RC}$ ) out of a total of 300 individuals that were collected in the field. Most non-marked individuals were juvenile barnacles $(n=16$, $\mathrm{RC}<7.8 \mathrm{~mm}$ ) that may have settled after chemical marking, although we also observed two non-marked adult barnacles ( $\mathrm{RC}>12.5 \mathrm{~mm})$, probably already present in the clump before marking. Such observations suggest a $94 \%$ success rate for the calcein tagging method in both juvenile and adult stalked barnacles $(\mathrm{RC}<20 \mathrm{~mm})$ for a period of approximately 2.5 months. Calcein marks were easily observed under epifluorescence, particularly in smaller individuals (Fig. 1). Not all of the four capitular plates observed per individual had visible or distinguishable fluorescent marks and some plates were broken or incomplete (tergum 13\%; scutum 5\%), which made them unsuitable for analysis.

\section{Relationship between maximum capitular plate length and maximum rostro-carinal length}

Maximum capitular (tergum and scutum) plate length measurements were highly and positively correlated among each other and with RC (Pearson's product-moment correlation, $r>0.98$ and significant at $p<0.01$ for all paired comparisons, $215 \leq n \leq 259$ pairs of observations), suggesting that either capitular plate ( $\mathrm{sc}$ or tg from the right or left side) may be used to estimate RC. 


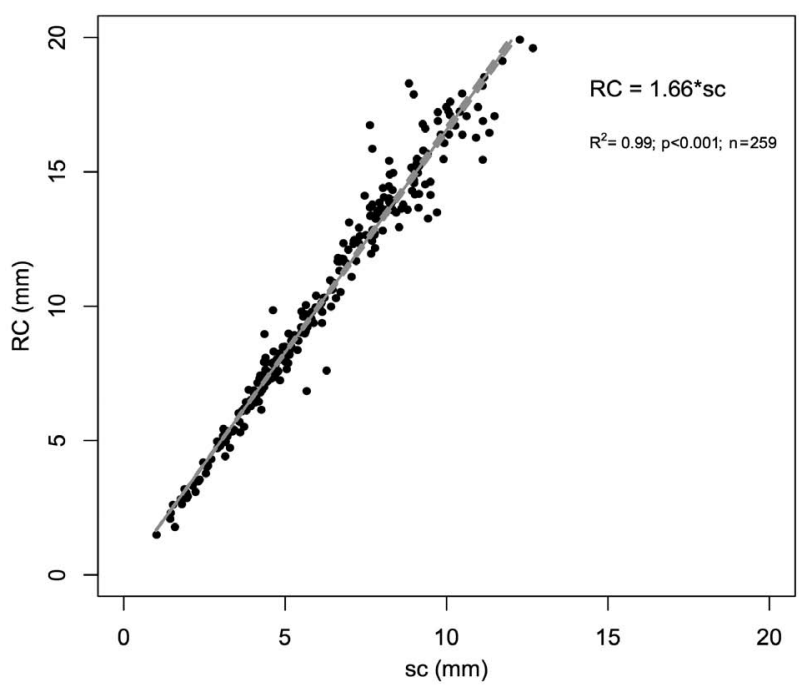

Fig. 2. - Relationship between maximum rostro-carinal length (RC) and maximum scutum length (sc) in P. pollicipes from Cabo Sardão (Portugal). Linear regression model prediction for the mean response value (solid grey line) is shown superimposed on the observed data (black dots).

The most parsimonious and significant linear model for describing the relationship between the $\mathrm{RC}$ length and scutum length ( $\mathrm{sc}$ ) had the form $\mathrm{RC}=1.66^{*} \mathrm{sc}$ (standard error for regression coefficient, $\mathrm{se}=0.008$; adjusted $\mathrm{R}^{2}=0.99 ; \mathrm{n}=259$ paired data; $\mathrm{p}<0.001$, Fig. 2). All measurements made in the scutal plates (sc_f and $\left.s c \_i\right)$ were converted to $R C$ units $\left(R_{C}\right.$ f and $R C \_i$, respectively) using the above-mentioned formula.

\section{Growth rate variation}

Monthly growth (dRC30) was highly variable $(0.00$ to $1.95 \mathrm{~mm}$ ) between individuals (Fig. 3). The most parsimonious generalized additive model explaining growth variation (deviance explained, $\mathrm{DE}=47.5 \%$; $\mathrm{n}=269 ; \mathrm{p}<0.001$ ) included barnacle initial size (estimated RC_i used as proxy for barnacle initial size)

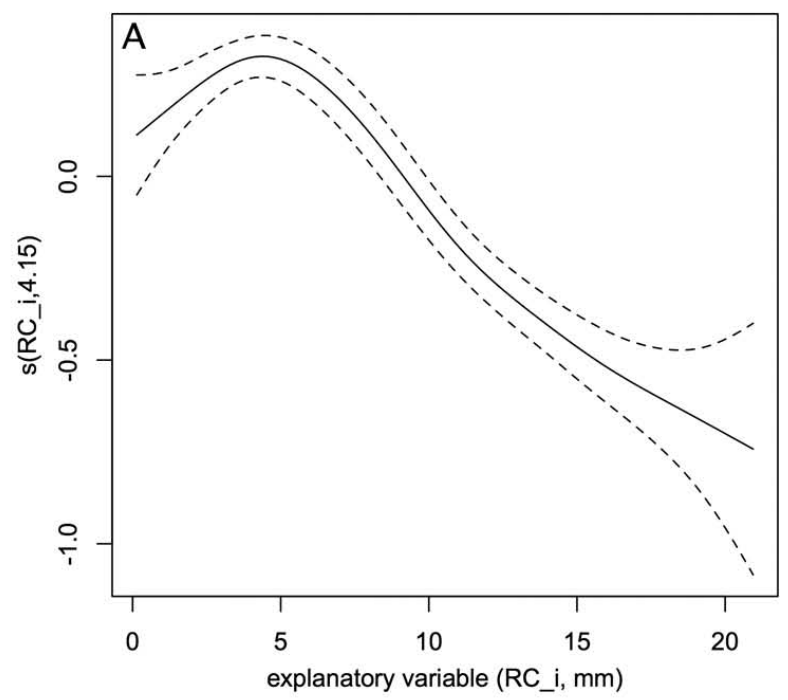

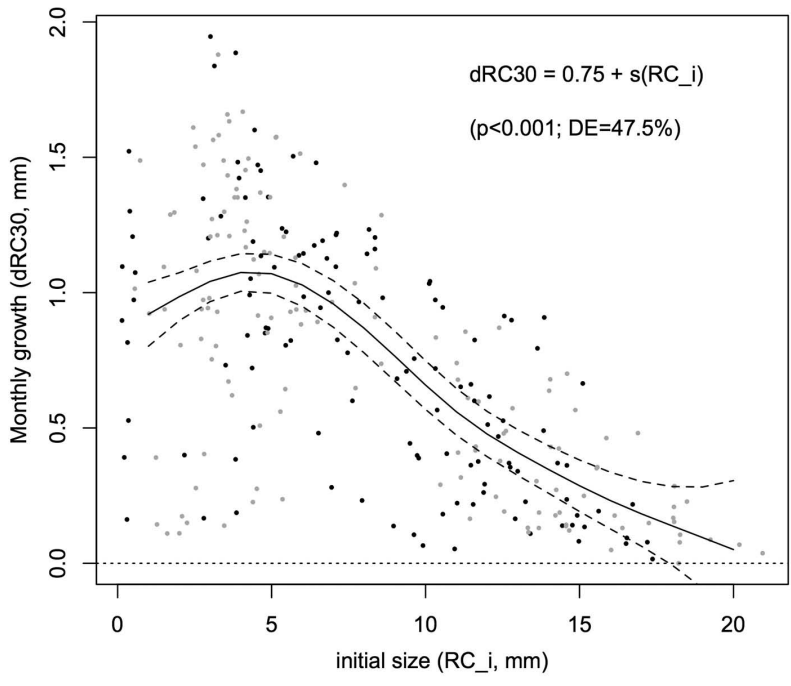

Fig. 3. - P. pollicipes monthly growth (dRC30) variation with initial barnacle size (RC i). Generalized Additive Model (GAM) predictions for mean (solid black line) and $95 \%$ confidence intervals (dashed black lines) are superimposed on the observed data for lowand high-shore levels (black and grey dots, respectively).

as the only explanatory variable, and had the form $\mathrm{dRC} 30=0.75+\mathrm{s}\left(\mathrm{RC} \_\mathrm{i}\right)$, where $s\left(\mathrm{RC} \_\mathrm{i}\right)$ is the smoothing function for the covariate (Fig. 4). No residual patterns were observed and the model was validated (Fig. 4B).

Growth rate in $P$. pollicipes decreased with barnacle size and was highly variable among individuals, particularly in smaller barnacles (Fig. 3). Average growth rates were higher in smaller juvenile barnacles (peaking at $1.1 \mathrm{~mm}$ per month for $5 \mathrm{~mm} \mathrm{RC}$ individuals), and gradually decreased with barnacle size (monthly growth rates of $0.5 \mathrm{~mm}$ for adult barnacles with $\mathrm{RC} \sim 12.5 \mathrm{~mm})$. Average growth rates observed in larger adults $(\mathrm{RC} \geq 18 \mathrm{~mm})$ of commercial interest was $<0.25 \mathrm{~mm}$ per month.

As expected, barnacle growth decreased with initial barnacle size but, contrary to our hypothesis, no effect of shore level on barnacle growth was detected (non-

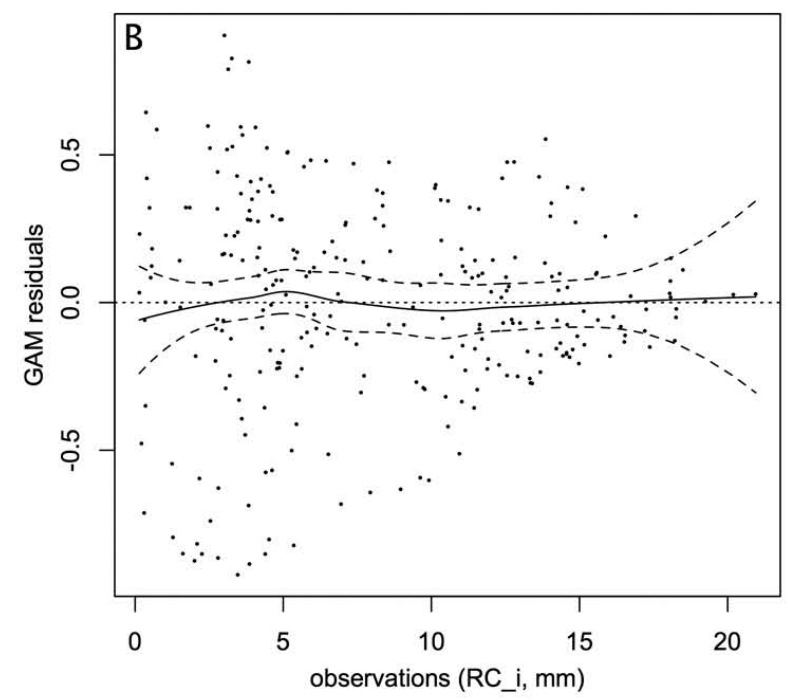

Fig. 4. - Generalized additive model (GAM) validation plots. A) smoothing function; B) standardized residuals for the optimal GAM plotted against observations. Loess fit predictions for mean (span 0.65; solid black line) and 95\% confidence intervals (dashed black lines) are superimposed on the observed data (black dots), showing no residual patterns. 
significant effect for factor Shore Level $(p>0.9)$ in the GAM model that included both explanatory variables, RC_i and Shore Level).

\section{DISCUSSION}

In this study we used a calcein solution $(200 \mathrm{mg}$ $\left.1^{-1}\right)$ to simultaneously mark overnight $(20 \mathrm{~h})$ several $P$. pollicipes clumps of individuals with different sizes $(<20 \mathrm{~mm} \mathrm{RC})$ collected in the field at different tidal levels (high and low shore) on a shore of SW Portugal. Chemical tagging with calcein had a high success rate (94\%) in marking both juvenile and adult barnacles for a period of at least 2.5 months, and can be considered a valuable method for easily obtaining reliable data in growth studies of $P$. pollicipes, an important marine resource, allowing its use in management models of barnacle fisheries such as the one proposed by Bald et al. (2006).

Our observations suggest a rapid increase in size during the first year, with most individuals reaching maturity ( $\mathrm{RC} \geq 12.5 \mathrm{~mm}$; Cruz and Araújo 1999) within one year. Growth rates varied with barnacle size, as has been previously observed (Cruz 1993, 2000, Cruz et al. 2010). An average non-linear trend in growth rate with size was observed. Mean growth rates were higher in juvenile barnacles (peaking at $1.1 \mathrm{~mm}$ per month for individuals with RC $\sim 5 \mathrm{~mm}$ ), and gradually decreasing with barnacle size (monthly growth rates of $0.5 \mathrm{~mm}$ for adult barnacles with RC $12.5 \mathrm{~mm}$ ). Mean monthly growth rates observed in larger adults of higher commercial interest ( $>18 \mathrm{~mm} \mathrm{RC)}$ was $<0.25 \mathrm{~mm}$.

Mean growth rate estimates presented here for the stalked barnacle $P$. pollicipes at C. Sardão (SW Portugal) are comparable to previous results of studies carried out in the same region (Cruz 1993, 2000, Cruz et al. 2010). When monitoring the size of 11 individual barnacles that had recruited onto a cleared surface, Cruz et al (2010) estimated an average growth of $1.3 \mathrm{~mm} \mathrm{RC}$ per month during their first year of life. The higher growth rates observed by Cruz et al. (2010) on juvenile barnacles may have been due to a lower intra- and interspecific competition pressure upon the animals that have settled on a cleared surface than upon animals that live and grow within an aggregate, such as the ones measured in the present study and by Cruz $(1993,2000)$. When mapping and measuring un-aged individuals within barnacle clumps, Cruz (2000), reanalysing data presented by Cruz (1993), estimated that on average, juvenile barnacles $(\mathrm{RC}<10$ $\mathrm{mm}$ ) grew $0.47 \mathrm{~mm} \mathrm{RC}$ per month (winter to summer), while adults (RC>10 mm) grew $0.11 \mathrm{~mm} \mathrm{RC}$ per month in the summer and $0.47 \mathrm{~mm} \mathrm{RC}$ per month in winter and spring. The growth rates presented here for juvenile barnacles are larger, in general, than had been previously reported. This might be due to a measurement of larger juveniles in Cruz (2000) than in the present study, as measurements done in Cruz (2000) were made in the field with callipers. The growth rates reported by Cruz (2000) for adult barnacles during the summer period are within the range of what we observed in the present study.
Growth rates were highly variable between individuals but, contrary to our expectations, were not higher in the low shore, as suggested by the size structure analyses of $P$. pollicipes carried out by Cruz et al. (2010). The study may not have been long enough to provide the expected variation. As only one site was considered, more studies and data including more sites are needed to ensure proper spatial replication. However, the manipulation procedure used in the method might disrupt the natural situation under which these barnacles normally live. Unlike low-shore populations, mid- to higher-shore $P$. pollicipes populations tend to aggregate in dense stands of barnacles, which the collection-marking-outplanting procedure might disrupt, possibly affecting the intra- and interspecific competition pressure under which these mid- to highshore individuals live and masking any putative variation in growth rates related to vertical level in intertidal habitats.

Though most variation in the stalked barnacle growth rate seems to be related to barnacle size, highly variable growth rates were observed between similar sized individuals, particularly in juvenile barnacles. This might be related to growth patterns associated with natural occurring phenomena that barnacle populations are subjected to, such as barnacle clump density, position within the clump and microhabitat. Helms (2004) studied juvenile growth in $P$. polymerus and compared growth rates from juvenile $P$. polymerus in different clump sizes and position within the clump. Growth rates were higher in peripheral barnacles and in barnacles occurring in smaller-sized clumps, possibly due to intraspecific competition for space and food between juveniles and adults within the barnacle aggregate (Helms 2004). More observations at suitable spatial and temporal scales and including ecologically relevant covariates are needed to explain the high intraspecific variability in growth rate observed in the present study.

Chemical marking techniques with calcein have a great potential in stalked barnacle growth studies, mainly because they allow mass marking of individual barnacles of different size cohorts within a short period (less than 1 day of manipulation) and involve less fieldwork time, which is a major advantage because this species lives on extremely exposed rocky shores. However, one major caveat of this method is that it does not allow individual growth to be followed over time, as animals must be sacrificed for data acquisition. Further adaptations to this method may partially overcome this issue, for example by tagging the same animals at different time intervals using calcein, which fluoresces with a different colour. The use of calcein as a chemical marker may lead to further experiments on this important resource and make it possible to test hypotheses addressing spatial and temporal variability in growth patterns at a multitude of scales.

\section{ACKNOWLEDGEMENTS}

We thank A. Helms for early discussion on the chemical marking methodology. This study is an out- 
put of the project "PERCEBES: Gestão, Ecologia e Conservação do Percebe em Portugal", funded by the Programa Operacional Pesca 2007-2013 (PROMAR) supported by the European Fisheries Fund (31-03-05FEP-11). David Jacinto was funded with a Fundação para a Ciência e Tecnologia (FCT) grant (SFRH/ $\mathrm{BD} / 28060 / 2006)$. The host institution had the support of the FCT (PEst-OE/MAR/UI0199/2011).

\section{REFERENCES}

Anderson D.T. 1994. Barnacles: structure, function, development and evolution. Chapman and Hall, London, $357 \mathrm{pp}$.

Bald J., Borja A., Muxika I. 2006. A system dynamics model for the management of the gooseneck barnacle (Pollicipes pollicipes) in the marine reserve of Gaztelugatxe (Northern Spain). Ecol. Modell. 194: 306-315. http://dx.doi.org/10.1016/j.ecolmodel.2005.10.024

Barnes M. 1996. Pedunculate cirripedes of the genus Pollicipes. Oceanogr. Mar. Biol. Annu. Rev. 34: 303-394.

Boukaici M., Bergayou H., Kaaya A., et al. 2012. Pollicipes pollicipes (Gmelin, 1789) (Cirripède, Lepadomorphe): étude de la croissance et de la dynamique des populations dans la région de Mirleft (sud ouest Marocain). Crustaceana. 85: 1073-1097. http://dx.doi.org/10.1163/156854012X651259

Cardoso A., Yule A. 1995. Aspects of the reproductive biology of Pollicipes pollicipes (Cirripedia: Lepadomorpha) from the southwest coast of Portugal. Netherlands J. Aquat. Ecol. 29: 391-396. http://dx.doi.org/10.1007/BF02084238

Chaffee J., Lewis C. 1988. Pedunculate barnacle stalk growth. J. Exp. Mar. Bio. Ecol. 124: 145-162. http://dx.doi.org/10.1016/0022-0981(88)90169-4

Cruz T. 1993. Growth of Pollicipes pollicipes (Gmelin, 1790) (Cirripedia, Lepadomorpha) on the SW coast of Portugal. Crustaceana. 65: 151-158. http://dx.doi.org/10.1163/156854093X00522

Cruz T. 2000. Biologia e ecologia do percebe, Pollicipes pollicipes (Gmelin, 1790), no litoral sudoeste português. $\mathrm{PhD}$ thesis, Univ. Évora, 328 pp.

Cruz T., Araújo J. 1999. Reproductive Patterns of Pollicipes pollicipes (Cirripedia: Scalpellomorpha) on the Southwestern Coast of Portugal. J. Crustac. Biol. 19: 260-267. http://dx.doi.org/10.2307/1549232

Cruz T., Castro J.J., Hawkins S.J. 2010. Recruitment, growth and population size structure of Pollicipes pollicipes in SW Portugal. J. Exp. Mar. Biol. Ecol. 392: 200-209. http://dx.doi.org/10.1016/j.jembe.2010.04.020

Ebert T.A., Russell M.P., Gamba G., et al. 2008. Growth, survival, and longevity estimates for the rock-boring sea urchin Echinometra lucunter lucunter (Echinodermata, Echinoidea) in Bermuda. Bull. Mar. Sci. 82: 381-403.

Frenkel V., Kindschi G., Zohar Y. 2002. Noninvasive, mass marking of fish by immersion in calcein: evaluation of fish size and ultrasound exposure on mark endurance. Aquaculture. 214: 169-183. http://dx.doi.org/10.1016/S0044-8486(02)00135-7

Helms A.R. 2004. Living on the edge: juvenile recruitment and growth of the gooseneck barnacle Pollicipes polymerus. M.Sc. Thesis, Univ. Oregon, 107 pp.

Hoffman D. 1984. Size-frequency distribution patterns of the juvenile stages of the pendunculate barnacle, Pollicipes polymerus Sowerby, 1833 (Cirripedia, Lepadomorpha). Crustaceana. 46: 295-299.
http://dx.doi.org/10.1163/156854084X00216

Jacinto D., Cruz T., Silva T., et al. 2010. Stalked barnacle (Pollicipes pollicipes) harvesting in the Berlengas Nature Reserve, Portugal: temporal variation and validation of logbook data. ICES J. Mar. Sci. 67: 19-25.

http://dx.doi.org/10.1093/icesjms/fsp226

Kaehler S., McQuaid C. 1999. Use of the fluorochrome calcein as an in situ growth marker in the brown mussel Perna perna. Mar. Biol. 133: 455-460. http://dx.doi.org/10.1007/s002270050485

Kilada R., Sainte-Marie B., Rochette R., et al. 2012. Direct determination of age in shrimps, crabs, and lobsters. Can. J. Fish. Aquat. Sci. 69: 1728-1733. http://dx.doi.org/10.1139/cjfas-2012-0254

Lambert G., Lambert C. 1996. Spicule formation in the New Zealand ascidian Pyura pachydermatina (Chordata, Ascidiacea). Connect. Tissue Res. 34: 263-269. http://dx.doi.org/10.3109/03008209609005270

Leips J., Baril C., Rodd F., et al. 2001. The suitability of calcein to mark poeciliid fish and a new method of detection. Trans. Am. Fish. Soc. 130: 501-507. http://dx.doi.org/10.1577/1548-8659(2001)130<0501:TSOCT $\mathrm{M}>2.0 . \mathrm{CO} ; 2$

Molares J., Freire J. 2003. Development and perspectives for community-based management of the goose barnacle (Pollicipes pollicipes) fisheries in Galicia (NW Spain). Fish. Res. 65: 485-492. http://dx.doi.org/10.1016/j.fishres.2003.09.034

Moran A. 2000. Calcein as a marker in experimental studies newlyhatched gastropods. Mar. Biol. 137: 893-898. http://dx.doi.org/10.1007/s002270000390

Page H. 1986. Differences in population structure and growth rate of the stalked barnacle Pollicipes polymerus between a rocky headland and an offshore oil platform. Mar. Ecol. Prog. Ser. 29: $157-164$ http///dx doi.org/10.3354/meps029157

Parada J., Outeiral R., Iglesias E., et al. 2012. Assessment of goose barnacle (Pollicipes pollicipes Gmelin, 1789) stocks in management plans: design of a sampling program based on the harvesters’ experience. ICES J. Mar. Sci. 69: 1840-1849. http://dx.doi.org/10.1093/icesjms/fss 157

Phillips N. 2005. Growth of filter-feeding benthic invertebrates from a region with variable upwelling intensity. Mar. Ecol. Prog. Ser. 295: 79-89. http://dx.doi.org/10.3354/meps295079

Russell M.P., Urbaniak L.M. 2004. Does calcein affect estimates of growth rates in sea urchins? In: Heinzeller T., Nebelsick J.H. (eds), Echinoderms: Munchen Proceedings of the 11th International Echinoderm Conference, 6-10 October 2003, Munich, Germany. Taylor \& Francis, pp. 53-57.

Sousa A., Jacinto D., Penteado N., et al. 2013. Patterns of distribution and abundance of the stalked barnacle (Pollicipes pollicipes) in the central and southwest coast of continental Portugal. J. Sea Res. 83: 187-194. http://dx.doi.org/10.1016/j.seares.2013.04.005

Van der Geest M., van Gils J.A., van der Meer J., et al. 2011. Suitability of calcein as an in situ growth marker in burrowing bivalves. J. Exp. Mar. Bio. Ecol. 399: 1-7. http://dx.doi.org/10.1016/j.jembe.2011.01.003

Wilson C.A., Beckman D.W., Dean J.M. 1987. Calcein as a fluorescent marker of otoliths of larval and juvenile fish. Trans. Am. Fish. Soc. 116: 668-670. http://dx.doi.org/10.1577/1548-8659(1987)116<668:CAAFM O> 2.0.CO;2

Zuur A., Ieno E., Smith G. 2007. Analysing ecological data. Springer, New York, 672 pp. http://dx.doi.org/10.1007/978-0-387-45972-1 